\title{
Modeling of thermal interaction between buried pipeline and icy soils
}

\author{
Nikolaeva M.V. \\ Department "Oil and gas business" \\ North-Eastern Federal University \\ Laboratory of geology of oil and gas fields \\ Institute of oil and gas problems SB RAS \\ Yakutsk, Russia, mv.nikolaeva@s-vfu.ru
}

\author{
Struchkova G.P. \\ Department of geoinformation systems \\ Institute of physical and technical problems of the North SB \\ RAS \\ Yakutsk, Russia
}

\author{
Atlasov R.A. \\ Department "Oil and gas business" \\ North-Eastern Federal University \\ Laboratory of geology of oil and gas fields \\ Institute of oil and gas problems SB RAS \\ Yakutsk, Russia
}

\begin{abstract}
In the article, a predictive calculation of buried pipeline with ice-bearing and ice-rich soils thermal interaction was carried out. To describe the thermal interaction of the pipeline with permafrost soils, the enthalpy Kronik model was chosen. Calculations are made taking into account the oil temperature along the pipeline length, the physical and mechanical characteristics, temperature of the enclosing soil, regional natural and climatic characteristics. The results of the thawing depth and thaw settlement calculating have shown that the thaw settlement value depends on the thawing halo and the soil ice-content, while the change in soil types along the pipeline must be taken into account. It is also necessary to take into account the change in soil types along the pipeline. The calculation being carried out for each pipeline site, taking into account the change in soil type and condition.
\end{abstract}

Keywords-buried pipeline; permafrost; thermomechanical model; ice content.

\section{INTRODUCTION}

The change in the temperature field of permafrost soils is the main factor in the activation of negative geocryological processes that affect the strength of structures, especially the strength of extended linear objects. Forecasting the interaction of buried pipelines with permafrost soils is an urgent task for ensuring the safety and reliability of pipelines functioning.

The process of heat transfer in the soil with phase change is described by the equation:

$$
\rho_{d}\left(C_{t h f}+L_{0} \frac{\partial W_{w}}{\partial T}\right) \frac{\partial T}{\partial t}=\lambda_{t h(f)} \frac{\partial^{2} T}{\partial x^{2}}+\frac{\partial^{2} T}{\partial y^{2}}+q_{v}
$$

where $\rho_{d}$ - dry density of a soil, $C_{t h f}-$ soil specific heat (thawed or frozen), $L_{0}$ - latent heat, $W_{w}$ - moisture content of frozen soil due to unfrozen water, $T$ - temperature, $t$ - time, $\lambda_{t h(f)}-$ soil thermal conductivity (thawed or frozen), $x, y$ coordinates, $q_{v}$ - power of the internal heat sources.

To describe the thermal interaction of pipeline with permafrost soils, the enthalpy Kronik model was chosen [1]. This model takes into account the variability of soil characteristics as a function of the change in their temperature. The enthalpy is a continuous function over the entire temperature spectrum and includes the thermal effect of phase transitions.

$T_{b f}$ corresponds to the temperature of the beginning of soil freezing.

$T_{w f}$ corresponds to the freezing point of bound water.

The proposed thermomechanical soil model describes the dependence of the change in heat capacity, thermal conductivity and enthalpy on temperature as follows:

I - thawed soil zone

The heat capacity and thermal conductivity of thawed soil are assumed to be constant at $T_{t h}>T_{b f}$ :

$$
\begin{gathered}
C_{I}=C_{t h}=\text { const } \\
\lambda_{I}=\lambda_{t h}=\text { const } .
\end{gathered}
$$

II - zone of phase transitions in freezing-thawing soil 

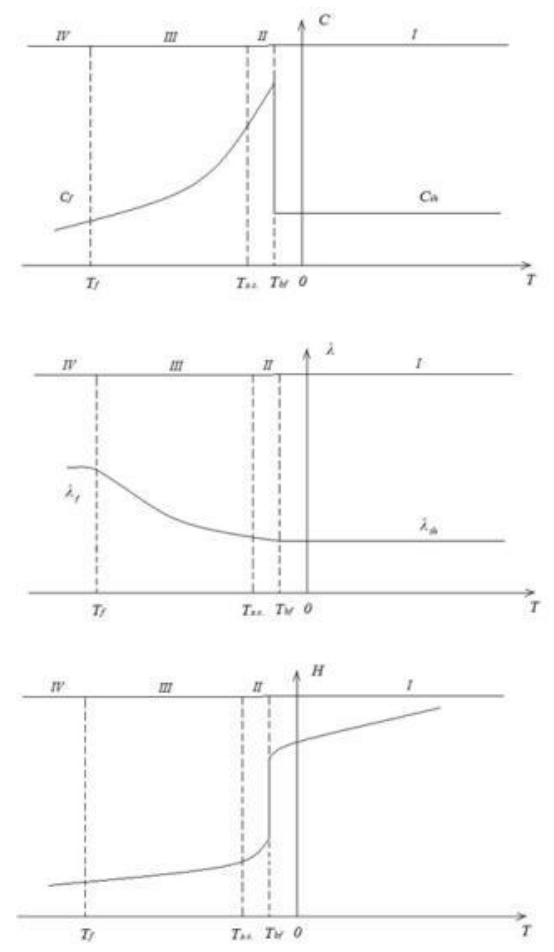

Fig.1. Thermomechanical soil model of Ya. Kronik.

The heat capacity and thermal conductivity of the soil in this zone are taken as temperature-dependent soil $T_{b f} \leq T \leq$ $T_{w f}$ :

where

$$
C_{I I}=C_{t h}-\frac{C_{t h}-C_{f}\left(T_{b f}-T\right)}{\left(T_{b f}-T_{f}\right)}+\frac{L \rho_{d}\left(w-w_{\mathrm{H}}\right)}{T_{b f}-T_{w f}}
$$

$$
\lambda_{I I}=\lambda_{t h}-\frac{\lambda_{t h}-\lambda_{f}\left(T_{b f}-T\right)}{\left(T_{b f}-T_{f}\right)}
$$

III - zone of freezing-thawing soil, while the amount of unfrozen water is close to the amount of absorbed water.

The heat capacity and thermal conductivity of the soil in this zone are also taken as temperature-dependent soil $T_{w f} \leq T \leq T_{f}$

$$
C_{I I I}=C_{f}+\frac{C_{t h}-C_{f}\left(T-T_{f}\right)}{\left(T_{b f}-T_{f}\right)}+\frac{L \rho_{d} d w}{d T}
$$

where

$$
\lambda_{I I I}=\lambda_{f}+\frac{\lambda_{t h}-\lambda_{f}\left(T-T_{f}\right)}{\left(T_{b f}-T_{f}\right)}
$$

IV - zone of frozen soil with temperature from $T_{f}$ and below.

In this zone, the heat capacity and thermal conductivity of the frozen soil are assumed to be constant:

$$
\begin{aligned}
& C_{I V}=C_{f}=\text { const } \\
& \lambda_{I V}=\lambda_{f}=\text { const }
\end{aligned}
$$

\begin{tabular}{|c|c|c|c|}
\hline \multirow{2}{*}{\multicolumn{2}{|c|}{ Temperature }} & \multicolumn{2}{|c|}{ Type of soil } \\
\hline & & $\begin{array}{c}\text { Sand, sandy } \\
\text { loam, coarse- } \\
\text { grained with } \\
\text { sandy } \\
\text { aggregate }\end{array}$ & $\begin{array}{c}\text { Loam, coarse- } \\
\text { grained with } \\
\text { loamy } \\
\text { aggregate }\end{array}$ \\
\hline \multirow{3}{*}{$\begin{array}{l}\text { Beginning } \\
\text { of soil } \\
\text { freezing }\end{array}$} & $\begin{array}{c}\text { waterlogged, friable, } \\
\text { (density } \gamma=1,0- \\
1,49 \mathrm{~g} / \mathrm{sm}^{3} \text { ) }\end{array}$ & -0.05 & -0.10 \\
\hline & $\begin{array}{c}\text { medium humidity, } \\
\text { dense, (density } \\
\gamma=1,50- \\
\left.1,79 \mathrm{~g} / \mathrm{sm}^{3}\right)\end{array}$ & -0.10 & -0.20 \\
\hline & $\begin{array}{c}\text { slightly wet, } \\
\text { overconsolidated, } \\
(\text { density } \gamma \geq \\
\left.1,80 \mathrm{~g} / \mathrm{sm}^{3}\right)\end{array}$ & -0.15 & -0.30 \\
\hline \multicolumn{2}{|c|}{ Beginning of bound water freezing } & -0.40 & -0.50 \\
\hline \multicolumn{2}{|c|}{ End of intensive phase transitions } & -3.0 & -5.0 \\
\hline \multicolumn{2}{|c|}{ Practically frozen state } & -5.0 & -7.0 \\
\hline
\end{tabular}

On the basis of experimental studies, the calculated soil freezing temperatures (Table 1) [2-4] were determined.
TABLE I. THE CALCULATED SOIL FREEZING TEMPERATURES

\section{RESEARCH METHODS}

The initial parameters are determined for the Republic of Sakha (Yakutia) climatic conditions. The average monthly temperatures is shown in Table. 2.

TABLE II. THE AVERAGE MONTHLY TEMPERATURES

\begin{tabular}{|c|c|}
\hline Month & Temperature \\
\hline I & -38.6 \\
\hline II & -33.8 \\
\hline III & -20.1 \\
\hline IV & -4.8 \\
\hline V & 7.5 \\
\hline VI & 16.4 \\
\hline VII & 19.5 \\
\hline VIII & 15.2 \\
\hline IX & 6.1 \\
\hline X & -7.8 \\
\hline XI & -27 \\
\hline XII & -37.6 \\
\hline
\end{tabular}

The start of operation is September, the duration of operation is 10 years. The problem of determining the thawing halo around the buried oil pipeline is solved numerically in the two-dimensional setting.

The process of heat transfer in the soil with phase change is described by the equation (1). 
The problem is considered in a rectangular domain. On the faces of this domain, the boundary conditions are given:

1. At the lateral and lower boundaries there is no heat exchange:

$$
\frac{\partial T}{\partial x}=0 ; \frac{\partial T}{\partial y}=0
$$

2. At the upper boundary, the effect of atmospheric air is taken into account.

The convective coefficient of atmospheric air with the daily surface of the soil is determined by the following equation [5]:

$$
\alpha_{\mathrm{K}}=0,93 \bar{U} \quad 6+\frac{6,2}{U^{2}}
$$

where $\alpha_{\mathrm{K}}$ is the convective coefficient, $U$ is the average wind speed above the Earth's surface.

The coefficient of heat exchange of atmospheric air with the surface of the soil is determined by the equation [6]:

$$
\alpha_{e f}=\frac{1}{\frac{1}{\alpha_{s n}}+\frac{\delta_{s n}}{\lambda_{s n}}}
$$

where $\alpha_{e f}$ is the coefficient of heat exchange, $\delta_{s n}$ is the height of the snow cover on the soil surface.

The coefficient of snow thermal conductivity is determined by the following equation [7]:

$$
\lambda_{s n}=0,0005+0,0019 \rho_{s}+0,006 \rho_{s}^{2}
$$

where $\lambda_{s n}$ - coefficient of snow thermal conductivity, $\rho_{s}$ density of snow, calculated by the Abe equation [8]:

$$
\rho_{s}=185,4 \cdot 10^{0,545 z}
$$

where $\mathrm{z}$ is the average monthly height of the snow cover.

The coefficient of heat exchange of atmospheric air with the snow cover surface is determined by the Yurgens equation [8]:

$$
\alpha_{s n}=6,47 \cdot U^{0.78}
$$

Calculations are made taking into account the oil temperature along the pipeline length, the physical and mechanical characteristics, temperature of the enclosing soil, regional natural and climatic characteristics. The problem is solved by the finite element method, the size of the calculation area is $80 \times 20 \mathrm{~m}$, the grid steps are $0.1 \mathrm{~m}$. To ensure sufficient accuracy of the solution, the time calculation step is 10 days.

When calculating the oil temperature is assumed constant (temperature $10{ }^{\circ} \mathrm{C}$ ), there is no thermal insulation of the pipeline.

The physical-mechanical and thermophysical properties of soils are taken in accordance with SNiP [9].

Based on the thermal calculation results the thaw settlement estimation is carried out taking into account the depth of thawing, compressibility and load on the frozen soil [10]:

$$
s_{t h}=k_{0} \xi+\alpha\left(P_{t h}+0,5 \rho_{\text {ск }} 1+w \xi\right) \xi
$$

where $s_{t h}$ is the value of the thermal pressure, $k_{0}$ is the thermal conductivity of thawing soil, $\alpha$ is the compressibility coefficient, $\xi$ is the thawing halo, $P_{t h}$ is the pressure on the thawed soil, $\rho_{s}$ is the soil density, and $w$ is the soil ice content.

Two types of soils (loam and sandy loam) with different values of ice content (ice-bearing and ice-rich) are considered.

\section{RESULTS AND DISCUSSION}

Type of soil - loam: density is $1400 \mathrm{~kg} / \mathrm{m}^{3}$; heat conductivity of thawed soil is $0.46 \mathrm{~W} / \mathrm{m}^{*}{ }^{\circ} \mathrm{C}$; thermal conductivity of frozen soil is $1.39 \mathrm{~W} / \mathrm{m}^{*}{ }^{\circ} \mathrm{C}$; the volumetric heat capacity of thawed soil is $1.6^{*} 10^{6} \mathrm{~J} / \mathrm{m}^{3 *}{ }^{\circ} \mathrm{C}$; the volumetric heat capacity of frozen soil is $1.47 * 10^{6} \mathrm{~J} / \mathrm{m}^{3} *{ }^{\circ} \mathrm{C}$; temperature of soil freezing is $-0.1{ }^{\circ} \mathrm{C}$; the temperature of the beginning of bound water freezing is $-0.5{ }^{\circ} \mathrm{C}$; the heat of water-ice phase transitions is $335000 \mathrm{~kJ} / \mathrm{m}^{3}$.

The thermomechanical model of loam with ice content $\mathrm{i}=$ 0.2 , describing the changes in the heat capacity $\mathrm{c}$, the thermal conductivity $\lambda$, and the enthalpy $\mathrm{H}$ of temperature, is as follows:

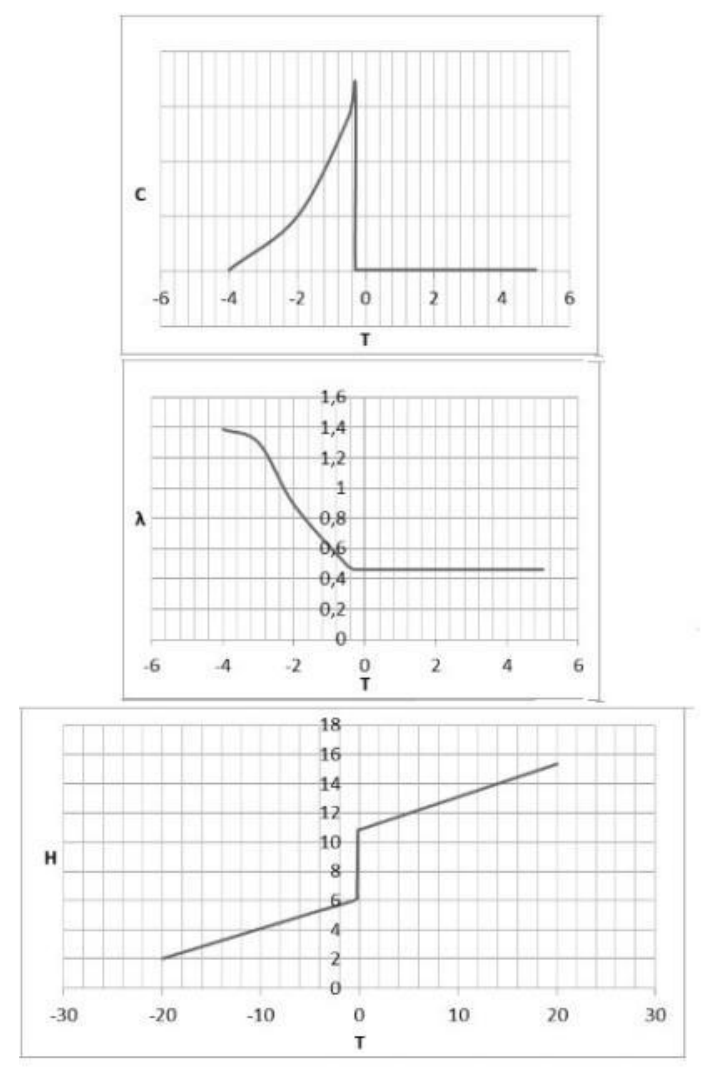

Fig.2. Thermomechanical model of loam with ice content $i=0.2$. 
The thermomechanical model of loam with ice content $\mathrm{i}=$ 0.4 , describing the changes in heat capacity $\mathrm{c}$, thermal conductivity $\lambda$ and enthalpy $\mathrm{H}$ as a function of temperature:

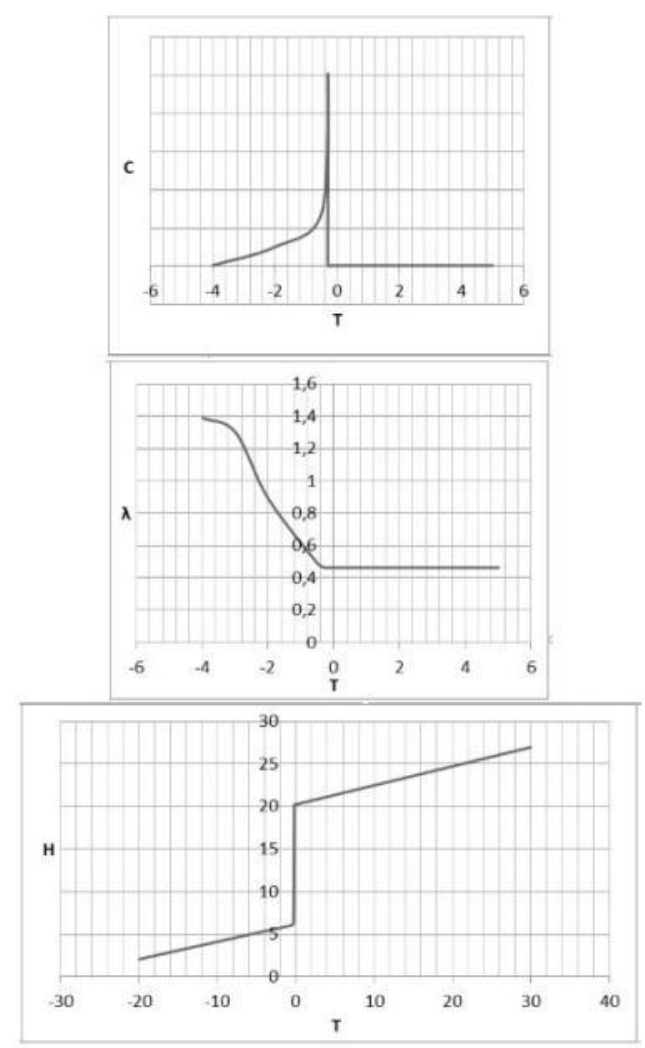

Fig.3. Thermomechanical model of loam with ice content $i=0,4$.

The results of calculating the thawing depth and the thaw settlement with the ice content $\mathrm{i}=0.2$ and $\mathrm{i}=0.4$ are given in Table 3.

\section{TABLE III. THAWING DEPTH AND THAW SETTLEMENT OF LOAM WITH THE ICE CONTENT I $=0.2$ AND I $=0.4$}

\begin{tabular}{|c|c|c|c|c|}
\hline $\begin{array}{c}\text { Operating time, } \\
\text { years }\end{array}$ & \multicolumn{2}{|c|}{ Thawing depth, $\mathrm{m}$} & \multicolumn{2}{c|}{ Thaw settlement, $\mathrm{m}$} \\
\cline { 2 - 5 } & $i=0,2$ & $i=0,4$ & $i=0,2$ & $i=0,4$ \\
\hline 5 & 2.6 & 2.0 & 0.31 & 0.35 \\
\hline 10 & 3.1 & 2.7 & 0.37 & 0.45 \\
\hline
\end{tabular}

Type of soil - sandy loam: density is $1400 \mathrm{~kg} / \mathrm{m}^{3}$; heat conductivity of thawed soil is $0.93 \mathrm{~W} / \mathrm{m}^{* \circ} \mathrm{C}$; thermal conductivity of frozen soil is $1.05 \mathrm{~W} / \mathrm{m}^{*}{ }^{\circ} \mathrm{C}$; the volumetric heat capacity of thawed soil is $1.89 * 10^{6} \mathrm{~J} / \mathrm{m}^{3} *{ }^{\circ} \mathrm{C}$; the volumetric heat capacity of frozen soil is $1.74 * 10^{6} \mathrm{~J} / \mathrm{m}^{3}{ }^{\circ}{ }^{\circ} \mathrm{C}$; temperature of soil freezing is $-0.3^{\circ} \mathrm{C}$; the temperature of the beginning of bound water freezing is $-0.5{ }^{\circ} \mathrm{C}$; the heat of water-ice phase transitions is $335000 \mathrm{~kJ} / \mathrm{m}^{3}$.

The thermomechanical model of sandy loam with the ice content $\mathrm{i}=0.2$, describing the changes in the heat capacity $\mathrm{c}$, the thermal conductivity $\lambda$, and the enthalpy $H$ of the temperature:

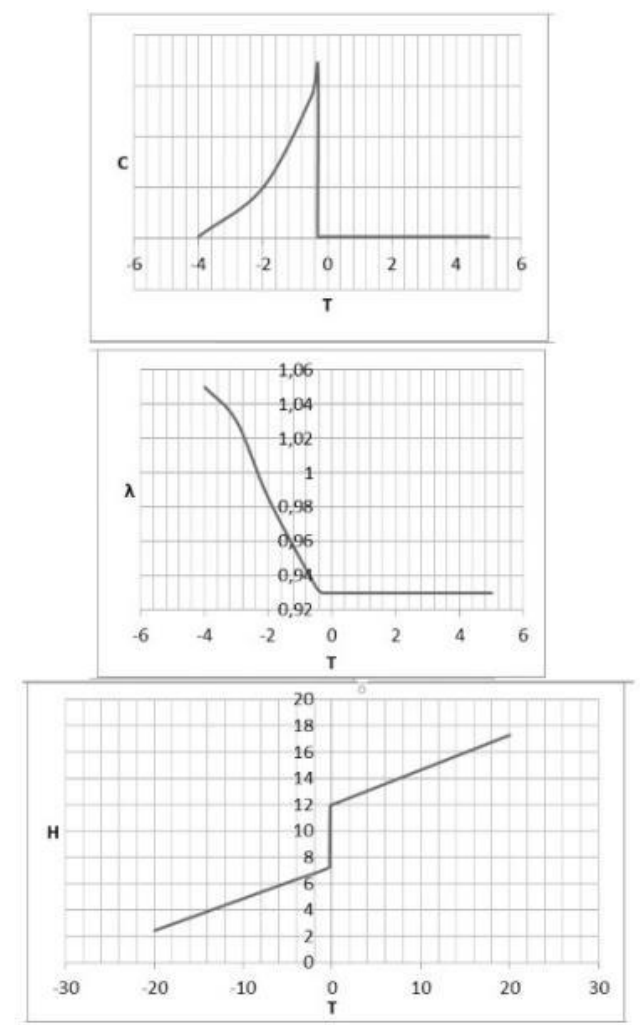

Fig.4. Thermomechanical model of sandy loam with ice content $i=0.2$.

The thermomechanical model of sandy loam with the ice content $\mathrm{i}=0.4$, which describes the changes in the heat capacity $\mathrm{c}$, the thermal conductivity $\lambda$, and the enthalpy $\mathrm{H}$ of the temperature:
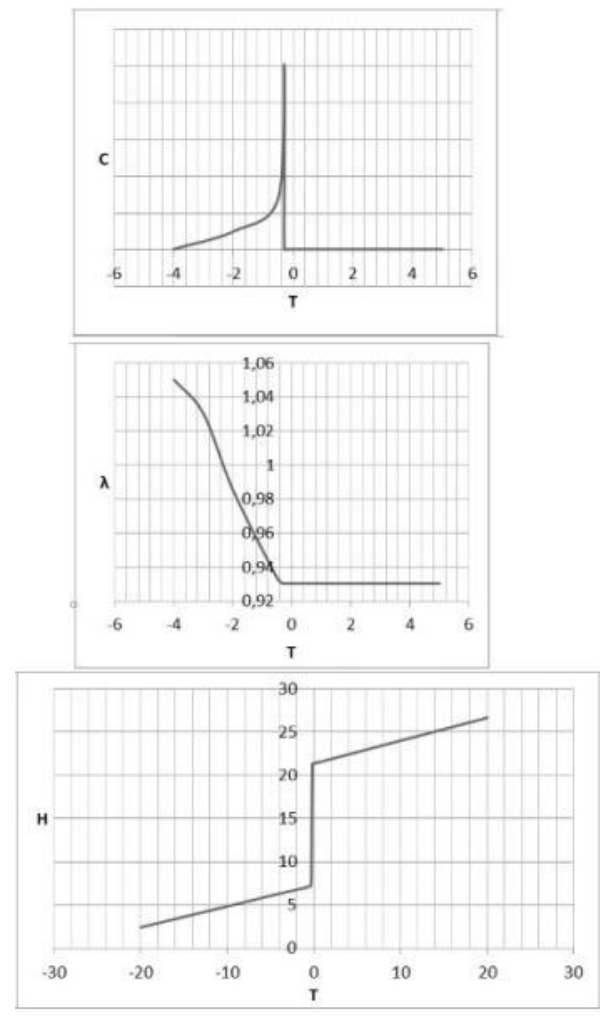

Fig.5. Thermomechanical model of sandy loam with ice content $i=0,4$. 
The results of calculating the thawing depth and the thaw settlement with the ice content $\mathrm{i}=0.2$ and $\mathrm{i}=0.4$ are given in Table 4.

\section{TABLE IV. THAWING DEPTH AND THAW SETTLEMENT OF SANDY LOAM WITH THE ICE CONTENT I $=0.2$ AND I $=0.4$}

\begin{tabular}{|c|c|c|c|c|}
\hline $\begin{array}{c}\text { Operating time, } \\
\text { years }\end{array}$ & \multicolumn{2}{|c|}{ Thawing depth, $\mathrm{m}$} & \multicolumn{2}{c|}{ Thaw settlement, $\mathrm{m}$} \\
\cline { 2 - 5 } & $i=0,2$ & $i=0,4$ & $i=0,2$ & $i=0,4$ \\
\hline 5 & 2.6 & 2.0 & 0.31 & 0.35 \\
\hline 10 & 3.1 & 2.7 & 0.37 & 0.45 \\
\hline
\end{tabular}

The value of the thaw settlement depends on the thawing halo and the soil ice content.

\section{CONCLUSION}

The results of this research show that the determination of thermophysical parameters of frozen and thawed soils is crucial part for evaluating the reliability of the pipeline linear section. Their properties strongly depend on the value of the ice content and temperature. In ice-rich soils the calculated value of the thawing depth is the least, since a significant part of the heat from the pipeline is expended on the water-ice phase transition, but thawing of ice-rich soils results in the greatest thaw settlement.

It is also necessary to take into account the change in the types of soils along the pipeline. The calculation should be carried out for each site, taking into account the change in the type of soils and their state.

\section{References}

[1] Ya.A. Kronik. Thermomechanical models of frozen soils and cryogenic processes. In: Rheology of Soils and Engineering Permafrost. AN SSSR. Moscow: Science, 1982, pp. 200-212.

[2] N.A. Tsytovich, Mechanics of frozen soils. Moscow: Higher School, Maxwell, 1973.

[3] N.A. Tsytovich, Z.A. Nersesova, Phase composition of water in frozen soils. "Materials on laboratory research of frozen soils". Moscow: Publishing House of the Academy of Sciences of the USSR, 1957, Vol.3, pp.14-20.

[4] E.D. Ershov, Yu.P. Akimov, V.G. Cheverev. Phase composition of moisture in frozen soils. Moscow: Moscow State University, 1979.

[5] A.V. Pavlov, Heat exchange of soil with the atmosphere in the northern and temperate latitudes of the USSR. Yakutsk: YaKN, 1975.

[6] A.V. Pavlov, Calculation and regulation of the permafrost regime of the soil. Novosibirsk: Science, 1980.

[7] M.K. Zhekamuhov, Fundamentals of the mechanics of snow. Nalchik: KBU, 2003.

[8] L.A. Bekhovykh, The fundamentals of hydrophysics. Barnaul: AGAU, 2008.

[9] SNiP 2.02.04-88. Foundations and foundations on permafrost soils.

[10] P.P. Permyakov, I.I. Rozhin, G. G. Popov, Numerical forecast of the temperature regime of the soil bed of buried gas pipeline in a changing climate, AIP Conference Proceedings, Vol.1907, Issue 1, 2017, pp. 030021-1-030021-6. 